\title{
PpUL38 Antibody
}

National Cancer Institute

\section{Source}

National Cancer Institute. ppUL38 Antibody. NCI Thesaurus. Code C129672.

Any immunog lobulin that recognizes phosphorylated forms of CMV apoptosis inhibitor UL38 protein. 